\title{
Self home blood pressure monitoring in pregnancy: how reliable is it?
}

\author{
Hemapriya L. ${ }^{1 *}$, Nagaraj Desai ${ }^{2}$, Ambarish Bhandiwad ${ }^{1}$
}

\section{${ }^{1}$ Department of Obstetrics and Gynecology, ${ }^{2}$ Department of Cardiology, JSS Medical College and Hospital, JSS} University, Mysuru, Karnataka, India

Received: 22 December 2017

Accepted: 06 January 2018

\section{* Correspondence:}

Dr. Hemapriya L.,

E-mail: drpriya_911@ @otmail.com

Copyright: (C) the author(s), publisher and licensee Medip Academy. This is an open-access article distributed under the terms of the Creative Commons Attribution Non-Commercial License, which permits unrestricted non-commercial use, distribution, and reproduction in any medium, provided the original work is properly cited.

\section{ABSTRACT}

Background: The use of automated blood pressure monitors in pregnancy has become increasingly popular, as more women tend to get involved in their healthcare. Not only does it reduce clinician visits, it also helps to eliminate the white coat hypertension.

Methods: We conducted a prospective study in the antenatal department of JSS Medical College and Hospital, Mysuru; over a period of one year, from July 2016 to June 2017. The blood pressures of 50 women were recorded at four different periods of gestation using the conventional 'Diamond mercury Sphygmomanometer' versus the automated 'Omron HEM 7130' home BP monitor and compared.

Results: The recordings of systolic blood pressure at home were consistently less than the office measurements at all periods of gestation. However, the difference was not statistically significant. The comparison of diastolic pressures revealed minimal variations between the mean of the office and home blood pressure recordings. The mean arterial pressure also revealed a similar trend.

Conclusions: Self-monitoring of blood pressure is a feasible and acceptable option to pregnant women. It might make antenatal care more effective, but we need further research to establish safety and efficacy, the impact on women and health professionals, and how best to use the results.

Keywords: Diastolic blood pressure, Home BP monitoring, Mean arterial pressure, Pregnancy, Systolic blood pressure

\section{INTRODUCTION}

Conventional blood pressure and heart rate assessment in pregnant women has relied mostly on few measurements in the physician's office. Such single measurements may be misleading because BP and heart rate vary according to various rhythms, and measurements may be influenced by external and internal stimuli, according to the patients sleeping or waking schedule, physical activity, diet, and emotional state.

The use of automated home blood pressure monitors has provided a method of $\mathrm{BP}$ assessment that may compensate for some of the limitations of casual measurements. ${ }^{1}$ It may allow for a more accurate and precise description of the variation in blood pressure patterns throughout pregnancy and its association with pre eclampsia, if any.

The use of self BP monitoring as an adjunct to office BP monitoring has been recommended by various international guidelines including the American society of hypertension, World Health Organization and the Joint National Committee on Prevention, Detection, Evaluation and Treatment of High Blood Pressure (JNC 7). ${ }^{2}$ Automated BP monitoring is also superior in the detection of white coat hypertension among pregnant women. ${ }^{3}$ We conducted a prospective study at the 
antenatal OPD of Department of Obstetrics and Gynecology at JSS Hospital, Mysuru, over a period of one year, from July 2016 to June 2017.

The aim of the study was to determine whether self home $\mathrm{BP}$ monitoring is superior to conventional BP measurements for the detection of gestational hypertension/pre eclampsia, and whether it can reduce the number of hospital admissions for patients with suspected pre eclampsia.

\section{METHODS}

A prospective study was conducted in Department of Obstetrics and Gynecology at JSS Hospital, Mysuru. Institutional ethical committee approval was obtained. The patients were recruited over a period of one year from July 2016 to June 2017. 58 women who were between the age of 18 - 35 years, and came to the antenatal clinic from the first trimester onwards were recruited for the study. Out of the 58 women, 8 were not included in the study as they had a miscarriage, or developed gestational hypertension, or were lost to follow up. Women with age $<18$ or $>35$ years, anemia $(\mathrm{Hb}<10.5$ gm\%), obesity (BMI >30), multiple pregnancy, molar pregnancy, spontaneous abortion, chronic hypertension; primary or secondary, renal, cardiac and connective tissue disorders, preexisting diabetes mellitus and hyperthyroidism were excluded from the study.

A team comprising of a consultant Obstetrician and a resident in Obstetrics and Gynecology were trained to record the blood pressure in the correct way as described below. The BP was measured according to a strict protocol using the Diamond Mercury Sphygmomanometer. All monitors were calibrated regularly and checked for accuracy at the beginning of the trial. The woman was asked to be seated in a quiet room with her right arm supported and the correct-sized cuff sited at the level of the heart. The first and fifth Korotkoff sounds were taken for systolic and diastolic BP respectively and a total of three readings were recorded at intervals of five to ten minutes. The recorded blood pressure was the average of the three readings.

Additionally, all women were taught how to monitor blood pressure at home using the OMRON HEM 7130 home BP monitor. They were asked to record their blood pressure every 4-6 hours from 8 AM to 10 PM every day, over a period of seven days, at the below specified intervals. The lady was instructed to take the readings in the sitting position (both legs on the floor, back supported, with arm at the level of the heart) after resting for five minutes. The frequency of monitoring was as follows

- At 8-14 weeks

- At 16-20 weeks

- At 22-26 weeks

\section{- At 28-36 weeks}

The mean of systolic, diastolic and mean arterial pressures was calculated and used for comparison with the mean office blood pressure recordings.

\section{Statistical analysis}

The summary statistics was done using mean, standard deviation and $95 \%$ CI of mean. The inferential statistics is done by using repeated measure ANOVA with bonfferoni post hoc test. All the measurements were done using SPSS version 21.0.

\section{RESULTS}

In our cohort of 58 women, 8 were excluded due to various reasons like spontaneous abortion, development of gestational hypertension, or being lost to follow up. The blood pressure data of the remaining 50 women was analyzed, and the results are described below.

The average age of the women was 23.6 years (range 18 35 years). $50 \%$ of women were primigravida. $27 \%$ were second gravidas, and the remaining had higher order pregnancy.

In paired comparisons of systolic blood pressure, the mean SBP recorded at home was consistently less than the office measurements. This phenomenon was observed in all four recordings throughout pregnancy. The mean difference in Systolic blood pressure in the Office BP recordings and Home BP recordings ranged from $3.1 \mathrm{~mm}$ $\mathrm{Hg}$ to $5.3 \mathrm{~mm} \mathrm{Hg}$. However, this difference was not statistically significant. The $\mathrm{P}$ value at all four intervals was greater than 0.001 .

On comparing the Diastolic pressures, we observed very minimal variations between the mean of the office and home blood pressure recordings. The mean difference in diastolic blood pressure ranged from $0.2 \mathrm{~mm} \mathrm{Hg}$ to 1.5 $\mathrm{mm} \mathrm{Hg}$. This was not statistically significant.

The comparison of mean arterial pressures revealed mean differences in pressures ranging from $1.2 \mathrm{~mm} \mathrm{Hg}$ to 2.7 $\mathrm{mm} \mathrm{Hg}$. Figure 2 shows the mean differences in the blood pressures recorded with the sphygmomanometer and the automated oscillometric device. There were greater variations in Mean arterial pressures during the third and fourth visits, in accordance with the changes in Systolic pressure, yet it did not reach statistical significance.

Hence, we concluded that Self Home monitoring of Blood pressure using an automated oscillometric device is comparable to the conventional method of recording blood pressure using a mercury syphgmomanometer in the physician's office. 
Table 1: Comparison of office $\mathrm{BP}$ and home $\mathrm{BP}$ recordings.

\begin{tabular}{|c|c|c|c|c|c|c|}
\hline \multicolumn{7}{|c|}{ Paired samples statistics } \\
\hline & & Mean & $\mathbf{N}$ & Std. deviation & Std. error mean & p-value \\
\hline \multirow{2}{*}{ Pair 1} & SBPO1 & 108.4380 & 50 & 8.26601 & 1.16899 & \\
\hline & SBPH1 & 105.3344 & 50 & 7.38018 & 1.04372 & 0.014 \\
\hline \multirow{2}{*}{ Pair 2} & DBPO1 & 69.6432 & 50 & 5.74076 & 0.81187 & \\
\hline & DBPH1 & 69.3876 & 50 & 5.68702 & 0.80427 & 0.770 \\
\hline \multirow{2}{*}{ Pair 3} & MAPO1 & 82.5748 & 50 & 5.82321 & 0.82353 & \\
\hline & MAPH1 & 81.3699 & 50 & 5.61514 & 0.79410 & 0.154 \\
\hline \multirow{2}{*}{ Pair 4} & SBPO2 & 109.4340 & 50 & 6.75844 & 0.95579 & \\
\hline & SBPH2 & 105.5660 & 50 & 7.44191 & 1.05244 & 0.000 \\
\hline \multirow{2}{*}{ Pair 5} & $\mathrm{DBPO} 2$ & 68.7740 & 50 & 7.18319 & 1.01586 & \\
\hline & DBPH2 & 67.5934 & 50 & 5.55580 & 0.78571 & 0.255 \\
\hline \multirow{2}{*}{ Pair 6} & MAPO2 & 82.4873 & 50 & 6.68339 & 0.94517 & \\
\hline & MAPH2 & 80.25 & 50 & 5.3 & 1.16645 & 0.013 \\
\hline \multirow{2}{*}{ Pair 7} & SBPO3 & 111.4260 & 50 & 7.84760 & 1.10982 & \\
\hline & SBPH3 & 106.7094 & 50 & 5.88685 & 0.83253 & 0.000 \\
\hline \multirow{2}{*}{ Pair 8} & DBPO3 & 69.9620 & 50 & 6.18926 & 0.87529 & \\
\hline & DBPH3 & 68.2220 & 50 & 5.53520 & 0.78279 & 0.062 \\
\hline \multirow{2}{*}{ Pair 9} & MAPO3 & 83.7819 & 50 & 6.12369 & 0.86602 & \\
\hline & MAPH3 & 81.0508 & 50 & 5.10063 & 0.72134 & 0.002 \\
\hline \multirow{2}{*}{ Pair 10} & SBPO4 & 112.8220 & 50 & 6.55760 & 0.92739 & \\
\hline & SBPH4 & 107.5010 & 50 & 6.29975 & 0.89092 & 0.000 \\
\hline \multirow{2}{*}{ Pair 11} & DBPO4 & 69.7940 & 50 & 5.26957 & 0.74523 & \\
\hline & DBPH4 & 68.2624 & 50 & 4.74477 & 0.67101 & 0.099 \\
\hline \multirow{2}{*}{ Pair 12} & MAPO4 & 84.1328 & 50 & 5.24163 & 0.74128 & \\
\hline & MAPH4 & 81.4056 & 50 & 4.41614 & 0.62454 & 0.002 \\
\hline
\end{tabular}

\section{DISCUSSION}

Self-monitoring of blood pressure at home is becoming increasingly popular with patients as well as with health care professionals. It is a proven fact in patients with hypertension that self-monitoring of blood pressure is more accurate than monitoring in the physician's office.

Magee et al observed that women with gestational hypertension found it more convenient to self-monitor blood pressure at home rather than visit their clinician more often for blood pressure monitoring. 4 Women who are at a higher risk for developing preeclampsia are currently advised more frequent antenatal visits for blood pressure monitoring. ${ }^{5,6}$ However, there are no specific guidelines as to how frequently the blood pressure should be monitored in high risk women.

Asymptomatic women without risk factors, who have one or two high blood pressure readings, are being advised hospital admission for blood pressure monitoring which is not cost effective. Earlier identification of rising blood pressure in asymptomatic women would allow better targeting of resources at those in need of close monitoring, and self measurement between clinic appointments could facilitate this. Also, office measurements are more likely to be erratic, due to patient anxiety; the so called "white coat hypertension," or due to the physical strain endured by the patient in reaching the crowded hospital. These factors can be eliminated by monitoring blood pressure at home, and more measurements can be taken, thus improving accuracy of the blood pressure recordings.

Will the women monitor blood pressure at home?

Pregnant women are usually highly motivated, and can be educated to undertake repeated self-measurements and comply with monitoring schedules. ${ }^{7}$ They can accurately record blood pressure data, and their anxiety levels are not increased, if they are properly counselled. Many clinicians have reported being encouraged by women's cooperation, competence, and genuine desire to participate in their healthcare. ${ }^{8-11}$

Self home blood pressure monitoring is more acceptable to pregnant women than more frequent clinic visits, hospital admission, or ambulatory monitoring. ${ }^{12-15}$

Taylor et al found self-monitoringof blood pressure more acceptable than 24 hour ambulatory monitoring; in a study of 78 healthy pregnant women who evaluated both home and ambulatory monitors at 35-37 weeks gestation, as home monitoring caused less discomfort and did not interfere with activities or sleep. ${ }^{16}$ In present study, none of the women reported any unwillingness to participate, 
nor any discomfort, or any difficulty in understanding the procedure or monitoring blood pressure.

\section{Accuracy of self-monitoring}

There are large number of home monitors available, but only few are validated for use in pregnancy and preeclampsia. Monitors which are validated for general use may not be accurate in pregnancy and may give false low readings, hence specific validation in pregnant women is a must, before self-monitoring can be used routinely to monitor women with hypertension in pregnancy. ${ }^{17,18}$ There are quite a few monitors which have been validated for home use in pregnancy using widely accepted protocols. ${ }^{19-23}$

However, factors such as obesity, especially the upper arm circumference have to be taken in account when considering self-monitoring of blood pressure in pregnancy. The monitor used in present study has been validated for use in general population, however, there are no specific validation criteria in India for use of self BP monitoring in pregnancy. We found the OMRON HEM 7130 monitor to be reliable for use in pregnancy, although it was tested only in normotensive women.

\section{Procedure of self-monitoring}

In essential hypertension, self-monitoring for a minimum of three days and ideally seven days is currently recommended. ${ }^{24}$ Present study followed a similar pattern of monitoring for seven days continuously at various pre specified periods of gestation.

The cut off for predicting hypertension in pregnancy has been placed at $135 / 85 \mathrm{~mm} \mathrm{Hg}$ using data from ambulatory monitoring in pregnancy, but the threshold has not been established firmly. ${ }^{25,26}$ Clear self-monitoring thresholds for hypertension in pregnancy have not been established as there is very limited data available comparing clinic thresholds with self-monitored blood pressure in pregnancy. ${ }^{24,27}$ However, variation of blood pressure in the different trimesters of pregnancy, makes it challenging to establish normal values of blood pressure. So even a rise of blood pressure by $10-15 \mathrm{~mm} \mathrm{Hg}$ in the third trimester may be a cause for concern although it is within the so called normal range $(<140 / 90 \mathrm{~mm} \mathrm{Hg}$ by clinic measurement). It is unclear whether monitoring frequency should change if blood pressure rises notably but remains below the threshold of $140 / 90 \mathrm{~mm} \mathrm{Hg} .{ }^{27}$

\section{Frequency of self-monitoring}

According to American guidelines, in women with chronic hypertension the diagnosis should be confirmed by multiple measurements and may incorporate home or other out-of-office blood pressure readings, but the frequency of monitoring in non hypertensive women has not been clearly defined. ${ }^{28}$ NICE guidelines on hypertension in pregnancy conclude that research is needed to determine the optimal frequency and timing of measurement as well as on the best way to detect proteinuria in women who have existing hypertension or other known risk factors for pre-eclampsia. ${ }^{29}$

To summarize, the potential advantages and disadvantages of home monitoring of blood pressure in pregnancy are listed below.

Table 2: Potential advantages and disadvantages of home monitoring of blood pressure in pregnancy.

\begin{tabular}{|ll|}
\hline $\begin{array}{l}\text { Potential } \\
\text { advantages }\end{array}$ & Potential disadvantages \\
\hline Increased accuracy & $\begin{array}{l}\text { Few monitors have been } \\
\text { validated for use in pregnancy }\end{array}$ \\
\hline Patient friendly & $\begin{array}{l}\text { Poor understanding of normal } \\
\text { blood pressure in pregnancy }\end{array}$ \\
\hline $\begin{array}{l}\text { Decrease healthcare } \\
\text { professional time or } \\
\text { reduce clinic visits }\end{array}$ & $\begin{array}{l}\text { No diagnostic thresholds from } \\
\text { home monitoring to identify } \\
\text { pre-eclampsia or gestational } \\
\text { hypertension }\end{array}$ \\
\hline $\begin{array}{l}\text { Identify white coat } \\
\text { hypertension }\end{array}$ & $\begin{array}{l}\text { False reassurance if woman } \\
\text { with white coat hypertension } \\
\text { subsequently develops true } \\
\text { hypertension in pregnancy }\end{array}$ \\
\hline $\begin{array}{l}\text { May reduce women's } \\
\text { anxiety or } \\
\text { medicalisation of care }\end{array}$ & $\begin{array}{l}\text { No evidence that earlier } \\
\text { detection of high blood } \\
\text { pressure through home } \\
\text { monitoring will alter } \\
\text { outcomes }\end{array}$ \\
\hline & $\begin{array}{l}\text { No evidence on optimal } \\
\text { frequency and timing of home } \\
\text { monitoring }\end{array}$ \\
\hline
\end{tabular}

\section{CONCLUSION}

Self-monitoringof blood pressure at home during pregnancy may prove to be an inexpensive and reliable tool to screen for hypertensive disorders in pregnancy. It is easy to use, and women can be taught to self monitor, and report to the clinician if the blood pressure crosses the cut off value (presently 140/90 mm Hg). Larger prospective studies are required to establish the efficacy of home blood pressure monitoring in women with hypertensive disorders of pregnancy, and whether it can be used as a decision making tool in women with hypertensive disorders.

\section{ACKNOWLEDGMENTS}

Authors would like to thank Cardiology Society of India, Karnataka Chapter for funding this study.

Funding: Cardiology Society of India, Karnataka
Chapter
Conflict of interest: None declared
Ethical approval: The study was approved by the
Institutional Ethics Committee




\section{REFERENCES}

1. Rey E, Pilon F, Boudreault J. Home blood pressure levels in pregnant women with chronic hypertension. Hypertens Pregn. 2007;26(4):403-14.

2. Pickering TG, Phil D, White WB. When and how to use self and ambulatory blood pressure monitoring. J Am Soc Hypertens. 2008;2(3)119-24.

3. Dehaeck U, Thurston J, Gibson P, Stephanson K, Ross S. Blood pressure measurement for hypertension in pregnancy. J Obstet Gynecol Can. 2010 Apr;32(4):32834.

4. Magee LA, von Dadelszen P, Chan S, Gafni A, Gruslin A, Helewa $M$, et al. Women's views of their experiences in the CHIPS (Control of Hypertension in Pregnancy Study) pilot trial. Hypertens Pregnancy. 2007;26:371-87.

5. National Institute for Health and Care Excellence. Antenatal care. NICE clinical guideline CG62. NICE, 2008.

6. Meads CA, Cnossen JS, Meher S, Juarez-Garcia A, Riet G, Duley L, et al. Methods of prediction and prevention of pre-eclampsia: systematic reviews of accuracy and effectiveness literature with economic modelling. Health Technol Assess. 2008;12.

7. National Institute for Health and Clinical Excellence. Hypertension in pregnancy. NICE clinical guideline CG107. NICE, 2010.

8. Kitagawa M, Akiyama Y, Omi H, Sago H, Natori M. Development and clinical application of a telemedicine support system in the field of perinatal patient management. J Obstet Gynaecol Res. 2000;26:427-34.

9. Rayburn WF, Zuspan FP, Piehl EJ. Self-monitoring of blood pressure during pregnancy. Am J Obstet Gynecol. 1984;148:159-62.

10. Rayburn WF, Piehl EJ, Compton AA. Clinical significance of home blood pressure monitoring during pregnancy. Clin Exp Hypertens Part B. 1985;4:63-73.

11. Naef RW, Perry KG Jr, Magann EF, McLaughlin BN, Chauhan SP, Morrison JC. Home blood pressure monitoring for pregnant patients with hypertension. J Perinatol. 1998;18:226-9.

12. Cartwright W, Dalton KJ, Swindells H, Rushant S, Mooney P. Home measurement of pregnancy hypertension. Professional Care Mother Child. 1993;3:8-9.

13. Cartwright W, Dalton KJ, Swindells H, Rushant S, Mooney P. Objective measurement of anxiety in hypertensive pregnant women managed in hospital and in the community. Br J Obstet Gynecol. 1992;99:182-5.

14. Denolle T, Weber JL, Calvez C, Getin Y, Daniel JC, Lurton O, et al. Diagnosis of white coat hypertension in pregnant women with teletransmitted home blood pressure. Hypertens Pregnancy. 2008;27:305-13.

15. Taylor RS, Freeman L, North RA. Evaluation of ambulatory and self-initiated blood pressure monitors by pregnant and postpartum women. Hypertens Pregnancy. 2001;20:25-33.

16. Reinders A, Cuckson AC, Jones CR, Poet R, O'Sullivan G, Shennan AH. Validation of the Welch Allyn 'Vital
Signs' blood pressure measurement device in pregnancy and pre-eclampsia. BJOG. 2003;110:134-8.

17. Natarajan P, Shennan AH, Penny J, Halligan AW, de Swiet M, Anthony J. Comparison of auscultatory and oscillometric automated blood pressure monitors in the setting of preeclampsia. Am J Obstet Gynecol. 1999;181:1203-10.

18. Chung Y, de Greeff A, Shennan A. Validation and compliance of a home monitoring device in pregnancy: Microlife WatchBP Home. Hypertens Pregnancy. 2009;28:348-359.

19. De Greeff A, Reggiori F, Anthony J, Shennan A. The Microlife 3AC1: an accurate blood pressure measurement device in pregnancy and pre-eclampsia. $\mathbf{J}$ Hypertens. 2006;24(suppl 4):S279.

20. Reinders A, Cuckson AC, Lee JTM, Shennan AH. An accurate automated blood pressure device for use in pregnancy and pre-eclampsia: the Microlife 3BTO-A. BJOG. 2005;112:1-6.

21. De Greeff A, Beg Z, Gangji Z, Dorney E, Shennan AH. Accuracy of inflationary versus deflationary oscillometry in pregnancy and preeclampsia; Omron MIT versus Omron M7. Blood Pressure Monit. 2009; 14:37-40.

22. Golara M, Benedict A, Jones C, Randhawa M, Poston L, Shennan AH. Inflationary oscillometry provides accurate measurement of blood pressure in preeclampsia. Br J Obstet Gynaecol. 2002;109:1143-7.

23. NICE. Hypertension: clinical management of primary hypertension in adults. NICE guideline CG127. 2011. Available at http://guidance.nice.org.uk/CG127.

24. Hermida RC, Ayala DE. Diagnosing gestational hypertension and pre-eclampsia with the 24-hour mean of blood pressure. Hypertension. 1997;30:1531-7.

25. Hermida RC, Ayala DE. Reference thresholds for 24-h, diurnal, and nocturnal ambulatory blood pressure mean values in pregnancy. Blood Pressure Monit. 2005;10:33-41.

26. Seventh report of the Joint National Committee on Prevention, Detection, Evaluation, and Treatment of High Blood Pressure. 2004. Available at www.nhlbi.nih.gov/guidelines/hypertension/ jnc7full.htm.

27. Lindheimer MD, Akbari A. Hypertension in pregnant women. In: Oparil S, Weber MA, eds. Hypertension: a companion to Brenner and Rector's the kidney. W B Saunders;2000:688-701.

28. National Institutes of Health. Working group report on high blood pressure in pregnancy. National High Blood Pressure Education Program;2000.

29. National Collaborating Centre for Women's and Children's Health. Antenatal care: routine care for the healthy pregnant woman. RCOG. 2008.

Cite this article as: Hemapriya L, Desai N, Bhandiwad A. Self home blood pressure monitoring in pregnancy: how reliable is it?. Int J Reprod Contracept Obstet Gynecol 2018;7:419-23. 